\title{
New Trends in Homeric Scholarship (NTHS)
}

\section{By Anton Bierl}

1. Introduction to Oral Theory and Retrospect
1.1 Two Separate Traditions of Research? (1-3)
1.2 Focus on Composition and Crisis: 1930-1980 (4-5)
1.3 Reactions and Strategies Until the Late 1980s (6-10)
1.4 Innovations around the 1980s (11)

\section{New Oral Poetry}

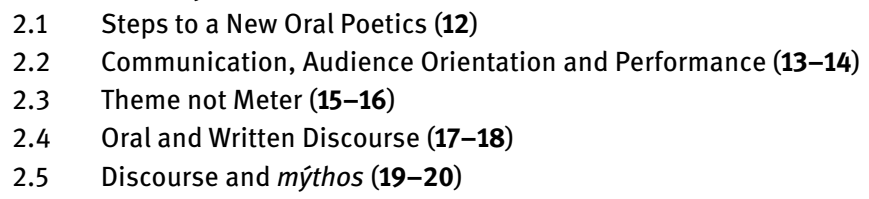

3. The Evolutionary Model
3.1 Tradition as Language, Diachrony in Synchrony (21)
3.2 Ages of Homer (22-23)
3.3 Panhellenization and Agonistics (24-28)
3.4 A Summary of the Evolutionary Model, Modifications and Response to Criticism (29-31)
3.5 Consequences
3.5.1 Neounitarian Quality and Malleability (32-35)
3.5.2 Traditional Art as an Oral Poetics of Ellipsis (36-37)
3.6 Relevance to Today: Multiforms, Web and Hypertext (38-40)

4. Further Topics and Related Themes
4.1 Biography (41)
4.2 Politics and Value Orientation (42)
4.3 Etymologies (43)
4.4 Myth (44-46)
4.5 Ritual (47-49)
4.6 Hero Cult and Epic Heroes (50-53)
4.7 Possible Influences from the Near East: Oriental Myths and Narratives (54-59)
4.8 Mise en abyme and Metanarrative Reflection (60-62)
4.9 Memory (63)

5. Conclusion and Prospect (64) 


\section{Introduction to Oral Theory and Retrospect}

\subsection{Two Separate Traditions of Research?}

With the new revised English edition of this commentary we seize upon a unique opportunity to add a new chapter to the Prolegomena (NTHS). This section closes the gap, especially between the chapters COM and FOR, that has widened since the early 1990s, or even the late 1980s, when the commentary project was first planned. At the same time, it attempts to embrace new approaches, in line with the German edition's spirit of accounting for the entirety of Homeric scholarship (COM 42). In particular, we wish to address the Anglophone reader.

At the beginning of the project, Latacz still spoke of two completely separate mainstreams, German-speaking and Anglophone scholarship (COM 25, 27), despite their tendencies toward convergence. One major goal of the original edition was to familiarize the German reader with English-speaking scholarship and to bring both lines to a fruitful synthesis (COM 42), as a complement to the Cambridge commentary. But I would no longer pessimistically say that our commentary was merely a German counter-part to the Cambridge commentary, a work designed to overcome the danger of standing on only one side of the great divide. The holistic scholarship to come, Latacz maintained, could make deeper and more synthetic sense of the original text (COM 27). I would assert that convergence has increased considerably since then, and that to some extent the present English edition actually represents this totalizing, synthetic tool for the beginning of the 21st century.

Why has Homeric scholarship, unlike any other field, fused into a unified international community? In today's globalized world, English has become the lingua franca - whether or not we ought to regret this fact cannot be discussed here. Because of the prevalence of English, scholars from all over the world, including the former European research nations such as Germany, Switzerland, Austria, France, Italy, the Netherlands and Spain, publish their main results in English or English translation, even as they continue to write in their mother-tongues, pursuing specific traditions. We can thus confidently maintain that the great divide mentioned above has been largely overcome since the commentary project was initiated. 


\subsection{Focus on Composition and Crisis: 1930-1980}

It is important to remember that the Parry-Lord hypothesis (see e.g. PARRY 1928; [1928] 1971; [1930] 1971; [1933] 1971; [1936] 1971; LORD 1960; 1991; 1995) was widespread on the American side of the Atlantic. Oral theory - another name for this approach - developed after the Second World War into a highly specialized field concerned with formulae and statistics. But despite the theory's predominance in Homeric research, another current of Anglophone Homeric scholarship in the vein of the New Criticism, which followed a basically unitarian approach, should not be forgotten. On the German-speaking side, on the other hand, one can observe a strong unitarian backlash against the analytic mode, which played a dominant role until the First World War, accompanied by a considerable fraction of Neoanalysis, with Schadewaldt as its leading figure.

The Parry-Lord approach constituted a major breakthrough in Homeric studies because it broke the deadlock of the lengthy yet unfruitful debate between Unitarians and Analysts. It thus transcended the debate by bringing the question onto a completely new footing grounded on up-to-date linguistics. But a onesided emphasis on formulaic matters, versification and compositional aspects led to a drastic decline in support from the 1970s onward. 'Formulaic analysis reached a dead end thirty years ago,' declared PowELL 2002, 7. The 'crisis' of oral poetry stems from the over-exploration of one important aspect in an originally balanced theory: oral improvisation via the use of formulaic elements, which after WoLf's (1795) seminal Prolegomena was neglected due to a lack of linguistic tools (LATACz 1979a), while Wolf's second hypothesis resulted in the deadend of Analysis based on nothing more than aesthetic judgment. Moreover, an overly mechanical and statistical approach paired with an almost blind belief in all its tenets fueled feelings of unease with the 'gospel of oralism' (WEST 2011a, 390).

\subsection{Reactions and Strategies Until the Late 1980s}

The integration of orality, oral theory and the Parry-Lord approach into 6 Homeric studies represented a major revolutionizing step. In Germany, this change took much longer and met with more resistance in finding a footing than it did in other scientific communities. This was because German-speaking Homerists, after the excesses of the Analysts during the so-called Third Humanism, which developed around the same time as PARRY's dissertation ([1928] 1971), were happy to detect the literary author and his artistry once again. In the swell of their unitarian turn, they accordingly felt an inner repulsion against seeing their 
genius destroyed once more by mechanical formulaics and put on the same level as 'primitive' Yugoslav guslar singers. Due to isolation during the Nazi period, moreover, and the ensuing total cultural collapse after 1945, the crisis was again healed through a revival of the Third Humanism. German-speaking Hellenists accordingly reinstalled Schadewaldt as 'hermeneutical pope' without questioning his role in the previous phase.

It was therefore LATACZ 1979a who brought German-speaking Homerists in closer contact with oral theory. They quickly found a way, of course, to reconcile this with the mainstream unitarian view: Homeric epic, according to Latacz and many critics after him, is based on a long oral prehistory dating back to Mycenaean times, but Homer as ingenious author and 'the first poet of the West' (LATACZ [1985] 1996, e.g. 15) can be explained only through literacy. The introduction of the Greek alphabet alone thus made it possible to compose such intricate poems.

While oral theory had a spotty history in the German-speaking world, where it has only now been fully embraced, it fell on far more fertile soil in other European countries, particularly Italy. All in all, the history of Homeric scholarship is defined by an ongoing and necessary search for the author and the true extent of his work (NANNINI 2010, esp. 9). Since antiquity, we can discuss the 'invention of Homer' (WEST 1999; GRAZIOSI 2002; see also BURKERT [1987] 2001), who, due to the need for an ingenious author, was retroactively assembled out of the fog of an obscure oral prehistory. Modern oral theory can thus add new nuances to an eternal Homeric question, especially with the balanced evolutionary model designed by NAGY 1996 (see also NAGY 1996a, esp. 29-63; 2002; 2003; 2008/09; 2009/10; first formulated NAGY 1981; further BIERL 2012; 2012a).

9 But additional developments should be considered. The revolutionizing results of PARRY $(M H V=1971)$ and LORD (1960; see also 1991; 1995) triggered an avalanche of books offering insight into traditional orality, oral mediality and pre-literary society; I mention only those by MCLUHAN 1962; HAVELOCK 1963; 1982; 1986; FInNEGAN 1977; ONG (1982) 2002 and Goody 1987. Yet since the late 1980s, some reluctance to write about formulae has been apparent. The exhausted reaction of stagnation, however, did not mean that the insight, which had almost grown to a communis opinio, was put aside. Thus for many critics it seemed impossible to ascribe any agency to Homer as a self-aware artist, or to claim that he might have consciously composed a traditional verse or alluded to other passages inside or outside his work. Few accordingly ventured to claim that a traditional epithet could occasionally reactivate its meaning in context. In this same vein one must note VISSER's (1987) attempt to reshape the improvisatory technique of versification, in which he maintains that the singer first consciously 
set a fundamental basis before filling in the rest of the verse. The debut of these insights by VISSER and BAKKER in the Anglophone world (see FOR 43) came at the end of the article FOR in the German edition, in which LATACZ still focused primarily on composition and formulaic theory.

Around the same time, scholars developed strategies to cope with these indi-

rect taboos. One such reaction was to ignore the traditional background (GRIFFIN 1980) and move to postmodern theory and new literary questions such as gender, feminism, poststructuralist deconstruction, intertextuality (PuccI 1987) and narratology (among others DE JoNG [1987] 2004; 1997 and see P). Another strategy stressed that Homer was 'master, not slave of his tradition' (DE JoNG 2012, 5). To this end, scholars attempted to illustrate the poet's nuanced and striking use of oral material and how his genius gains stature when viewed against the traditional background (MARTIN 1989; JANKO 1992; TAPLIN 1992). A revival of originally German-centered Neoanalysis also emerged, shifting to the Anglophone realm and gradually integrating orality, intertextuality and to some extent narratology (P) into a productive new tool. According to the Neo-Neoanalysts, the creative author incorporates mythic motifs via transference and manipulates other contemporary narration in oral, crystallized or written form, such as myths and Cyclic epics (Kullmann [1984] 1992; 1992; Willcock 1997; West 2003a; TsaGALIS 2008). Cutting-edge research in this area involves the coexistence, interaction and near-fusion of orality with Neoanalysis (BURGESS 2006; TSAGALIS 2011; MoNTANARI et al. 2012). I thus venture to assert again that, with these recent trends, Homeric scholarship has finally overcome the great divide mentioned above.

\subsection{Innovations around the $1980 \mathrm{~s}$}

There have been a series of so-called turns in the humanities since the 1980s. 11 After the linguistic turn, we witnessed the arrival of a performative, a visual and a spatial turn. In light of these turns, I would assert that Homeric oral theory is one of the most innovative fields of contemporary classical philology as it reflects the history of cultural debates in the late 20th and early 21st centuries. Pace UlF 2011, esp. 13-15 (see also 2010a), PARRY's insight is neither romanticizing in the vein of HERDER and WOLF, nor does it reflect the nationalistic-völkisch attitude of the 1920/30s, nor can today's representatives of orality be tarnished by these sweeping generalizations. To the contrary, PARRY's (1928) familiarity with contemporary linguistics allowed him to some extent to anticipate the ensuing linguistic turn. In addition, Parry developed his idea of traditional themes simultaneously with PROPP's ([1928] 1968) narrative functions, paving the way for folklore analysis. LORD 1960 had already addressed performance and was a trendsetter in 
regard to linguistic and performative approaches, taking into account the visual potential of language. He also introduced anthropology and cross-cultural comparative inquiry into his research. All in all, early Greek culture, and in particular Homeric epic, as the 'closest foreign' (HöLscher [1965] 1994, 278), could function as a historical foil to the usual perspective of bookish literacy, leading to overall interest in orality over the last forty years.

\section{New Oral Poetry}

\subsection{Steps to a New Oral Poetics}

It is immensely challenging to develop a viable concept of an oral poetics based on the vast cross-cultural comparative material of oral epic (see FolEY 2005), something LORD 1960 already had on his agenda (see also EDwARDs 1997, esp. 282-283). What led to many misunderstandings was Notopoulos' (1949) endeavor to define oral poetics in terms of origins, primitivism, parataxis, loosely linked, serial narration without hypotactic subordination, 'like beads on a string' $(1949,6)$. Seen in this light, the creative genius Homer is reduced to an artless rhapsode, a puppet on a string energized by mechanical and traditional expertise. Contrary to this conclusion, a thoroughly innovative, revised form of oral aesthetics appeared on the horizon. Against NotOPOulos' scenario, FolEy (1991; 1995; 1997; 1997a; 1999) and many other critics along with him outlined a far more positive picture of traditional art. MARTIN 2000 detected the creative tendency to incorporate and 'wrap up' multiple side-narratives and myths in an intra- and intertextual manner, and BAKKER 2013, 157-169, recently called this technique distancing himself from the term 'intertextuality' - ' interformularity.'

\subsection{Communication, Audience Orientation and Performance}

Before coming to a description in positive terms, we must envisage the twosided communication model of sender and recipient, both of whom, in the communicative triangle, encode and decode a message. Following the excessive focus on versification and/or composition, and accompanying the simultaneous shift in the 1980s from an aesthetics of production to one of reception, the other side of the coin, an audience that listens and reacts to the oral singer, has come to the fore. In the grand scheme of oral poetics we must never forget that the song is addressed to recipients who have developed specific capacities to appreciate such forms. Homeric orality is thus the dynamic communication of traditional 
epic contents and formulae played before a live audience that pays attention to the narration and responds with pleasure and enchantment.

The key term for this communicative process is performance, which is usually associated with theater; LORD 1960 spoke of 'composition-in-performance' on the side of the singer-producer, and we could add reception-in-performance on the side of the audience. Furthermore, critics have emphasized the aspect of mimesis in performance; in vivid, visual clarity, enárgeia, the word of a heroic past is reenacted before a fascinated audience. The re-actualization of memories of the past entails re-performance of an ever-evolving story. We could thus speak of reperformance in composition and reception. Through verbal visualization, deixis and mimesis, the singer fictionalizes the act of cognitive perception, and the listener is involved in a story that becomes real in the here and now before his mind's eye. Like an actor, the singer reenacts, almost theatrically, voices of the past; persons and stories are recreated via multimodal mimesis and become real; listeners become spectators. At the same time, the singer acknowledges the truth of his reenactment and understands, as a master of the truth, what he remembers as a true past guaranteed by the Muses. By 'pointing at the past,' he draws things into the present (BAKKER 2005, esp. 76-91).

\subsection{Theme not Meter}

In older orality research, the emphasis was on formulae produced in response to metrical needs. As a result, thematic context was mechanistically excluded, as if language, as an independent agency, could be separated from semantic and narrative meaning. But language is always constituted along a form-meaning continuum; similarly recurring situations build frames where formulae are shaped in context. The Lord-Parry theory has thus recently been productively linked with cognitive linguistics: analogous to language-acquisition processes, the singer and recipient acquire their traditional tools in an ongoing situational and usage-based context-form-meaning symbiosis. Meaning and idiomaticity emerge in instance-based contexts via patterns, building blocks, templates and frames, and finally crystallize into a sort of language produced by the constant quotation of previous situations in routinization. ${ }^{1}$ Thus not meter but themes are the basic constituents of epic discourse and determine metrical design. In

1 See the conference 'Oral Poetics and Cognitive Science’ organized by Cristóbal Pagán Cánovas (Murcia, Spain) and Mihailo Antović (Niš, Serbia) at the Freiburg Institute for Advanced Study, 24-26 January 2013 and the Acta to appear. 
this respect, formulae are akin to miniature themes possessing a far more complicated background story. Or to put it in NAGY's words (1990a, 23): 'A distinctive epithet is like a small theme song that conjures up thought-association with the traditional essence of an epic figure, thing, or concept.'

Due to the loss of interest in formulae, moreover, Homerists now deal more in themes and story-patterns, larger traditional forms already targeted by LORD 1960, 68-123, 158-197. The largest forms of all are myths, as traditional narrations with partial societal relevance (see BURKERT 1979, 23: 'myth is a traditional tale with secondary, partial reference to something of collective importance'; italics: W. B.), and one could to some extent regard an entire epic like the Iliad as a myth in this sense.

\subsection{Oral and Written Discourse}

Another facet of recent oral theory involves questioning the neat difference between written and oral. We are accustomed to thinking of oral, first of all, as the other, the eccentric. But in JAKOBSon's distinction of opposites, the oral is the unmarked, the general and usual status, whereas the written is the marked, special form (JAKOBSON [1957] 1984, 47). If we regard all communication records across the globe in this way, most are normal speech and oral, and only a small portion are written down in a book or other media. In addition, the distinct nature of oral poetry is not essential and quite complex (BAKKER 1997, 18-32; 2005, 38-55; FOLEY 1997, 162-164). Already LORD 1960, 124-138, accordingly spoke of dictation or better transcript, with orality recorded in literacy. Homer could have used the new technique of the alphabet and literacy somehow, of course, without changing his manner of composition - better, composition-in-(re)performance - or style. Some scholars now use the term 'oral-derived traditional texts' (e.g. FolEY $1997,163)$ that encapsulate tradition. Others speak of secondary orality as an artistic device supposedly creating the effect of oral archaism (UlF 2010, 297-301).

In transcripts we have a form of text, and if we analyze a performance-in-transcript as a record, we can discuss text. A performance and reperformance are somehow a multifaceted 'text' as well, in the sense of a varied tapestry. The Greek metaphor for composition-in-performance is weaving; a multiform product of poikilía of ongoing mouvance (ZUMTHOR 1972, esp. 73 and 43-47, 65-75; 1987, 160161) and variance (CERQUIGLINI 1989, esp. 111) is produced over a long period of time in endless reperformances (see NAGY 1996, 7-38). Its streamlining process results in a growing tapestry that can be identified as textualization (NAGY 1996a, 40). If we broaden the meaning of text in this manner, it becomes possible to speak of oral intertextuality and narratology, as practiced e.g. by BuRGESs (2006) 
in an innovative synthesis of Neoanalysis and oral theory - whereas mainstream narratology (e.g. DE JoNG 1997) fails to address the issue of orality.

\subsection{Discourse and mýthos}

Recent research has shown that such transcripts provide the record of a 19 text possessing all the features of ordinary speech. As noted above, speech is unmarked discourse in comparison to literate discourse, its marked opposite. For that reason KIPARSKY 1976 and then BAKKER (1997; 1997a) fruitfully applied the tools of discourse analysis (e.g. CHAFE 1988; 1994) and pragmatics to Homeric texts. Thus Homeric texts contain the same constituents as those found in transcripts of oral speeches taken from daily life, meaning that the message is constructed out of small chunks or building blocks consisting of around four to five words. The information units are set in parataxis, with strong emphatic particles and deictic indications that channel the evident sense of flux in words, with syntactic subordination reduced to a minimum. An artful text like the Iliad, however, with its complex Kunstsprache in vocabulary and multifaceted forms, is not unmarked, ordinary speech but marked, special speech.

In an important book, MARTIN 1989 emphasized that Homeric epic (as épos or 'word') is mýthos, i.e. authoritative, special speech. Direct speeches inserted by figures are also mýthoi and, in AusTiN’s (1962) 1975 terms, speech-acts with a particular performative goal such as blame, praise, admonition, agonistic conflicts or attempts to outdo an opponent. In this pragmatic perspective, not only the numerous character speeches but also the entire Iliad is mýthos, since as authoritative, special speech it aims at winning within a competitive occasion, an aristocratic feast or, later, a large popular festival. In this regard, the symbiosis and interplay between myth and ritual can also be applied to Homeric poetry. According to NAGY 1989, x-xi, the mýthos of Homeric epic is reenacted and periodically reperformed during occasions with a ritual dimension, i.e. feasts or festivals, particularly the Athenian Panathenaia. MARTIN 1989 also emphasized that the voice of the main hero, Achilleus, aligns closely with the narrator's voice, and that the two, aoidé and épos in BAKKER's terminology (2013, esp. 1-12), are prone to overlap. 


\section{The Evolutionary Model}

\subsection{Tradition as Language, Diachrony in Synchrony}

The real breakthrough in recent trends of Homeric orality studies is the evolutionary model of Homeric textualization by NAGY (1981; 1996, 107-206; 1996a, 29-63; 2003, 2-3; 2008/09, 1-72 [P§1-185]; see also FrAME 2009, 515-647, and BIERL 2012). ${ }^{2}$ Along with LORD 1960, Nagy regards Homeric tradition as a system of language. And as a linguist, NAGY $(2003,1)$ departs from the twin distinctions of DE SAUSSURE [1916] 1972, 117: 1. Langue, the general underlying structure or system of all speakers, vs. parole, the individual, concrete expression of a single speaker; 2. diachrony vs. synchrony, perspectives from the outside used for theoretical and abstract modeling. We normally look at the world through the perspective of synchrony - i.e. how reality appears at a given historical moment. But diachronic consciousness permits a view into the deeper levels of any phenomenon. Evolutionary awareness therefore always tries to evaluate cultural products as diachrony in synchrony. In this interplay, synchronically false circumstances can be explained by diachronic skewing; that is, at a theoretical level one can shift from any point backward or even forward in time, also mixing up two synchronic views in diachrony. The epic performer thus speaks about song and musical accompaniment by a phórminx, whereas in other instances he uses the word 'saying' for his Muse. In addition, Homeric hexameters reduce melody to a regulated recitative (parakatalogê) without music. Therefore in instances where idealized singers, like Demodokos in the Odyssey, perform within the epic action, older strata that at a later stage are no longer synchronically true are reactivated (NAGY 1990, 20-21; BIERL 2012).

\subsection{Ages of Homer}

With a diachronic awareness, we see that both Homer and the epic are constructs. 'The epic' and 'Homer' do not exist, for at any given moment in time we

2 By accepting this model, I cannot hide my modest dissent from the views held by WEST, in particular from the chapter HT in this volume and from WEST 2011 and 2011a. That our text is based on the edition by WEST is well-known. But this model has also repercussions on the constitution of the Iliadic text. On the dispute between WEST and NAGY in BMCR on these matters, see NAGY 2000 (review of WEST's edition in BMCR 2000.09.12); WEST (2001) 2011 (response in BMCR 2001.09.06) and 2004 (BMCR 2004.04.17). 
have a diachronically different picture of the genre and Homer. We must accordingly refer to 'ages of Homer' as he manifested himself in time and space (NAGY 2008/09, 2 [P§6]; 2009/10, 1 [Introduction §1]). Homeric epic represents the example par excellence of how diachrony exists within synchrony. Behind Homer lies a long oral past, the dark background of a vivid tradition in which aoidói composed oral songs as they performed them. This fact molds both form and content, affecting the specific manner of narration as well as the meter and the Homeric Kunstsprache. It is also a well-known feature of Homeric epic that it can shift easily between different forms of historic-linguistic development according to the needs of the hexameter. Even more to the point, the Iliad deals with events from a remote and idealized past, a dark age in the 14th or 13th century BC told from the perspective of a much later period.

Taken altogether, Homer and his monumental epics, the Iliad and the Odyssey, emerged only gradually in a long historical process extending from an obscure Mycenaean past into the 6th and 5th centuries BC, with a period of transition in the 9 th and 8th centuries. We must also reckon with further, minor developments down to the age of Aristarchus. We are told that Hipparchos regulated the agôn of the Panathenaia: in the competition, the two monumental poems of Panhellenic status were now to be performed at full length in alternation, one rhapsody following the other in a kind of relay (Plat. Hipp. 228b). This agonistic regulation affected the evolution of the text. At this stage, the oral tradition could be transformed into a continuous narration of enormous size that was then, in the age of writing, transmitted as text, taking the form of a script. Our 'Homer' thus stems from a snapshot of a historical moment as well as a retroactively biographical construct, and the Homeric epic evolves into a monumental text of pedagogical purpose for Hellas as a whole under specific historical circumstances (see NAGY 1996; 1996a; 2002; 2003; 2008/09; 2009/10; FRAME 2009, 515-647; BIERL 2012; [in press]). Consequently, the elaborate plot arises via ongoing retardations from much shorter songs stitched together on the principle of variation and combination.

\subsection{Panhellenization and Agonistics}

The driving force of this evolutionary process toward a monumental epic is

an emerging Panhellenism, i.e. a growing awareness that the divided Greek cities had a common cultural and ethnic heritage. Following the total decline during the so-called Dark Age and the ensuing immigration from the mainland, Greek life began to flourish anew in Asia Minor; the increasing common ground even led to ethnic leagues, such as the Aeolic and later the Ionic confederation of 
twelve major cities. In addition, Panhellenism fostered a tendency to relegate epichoric and local perspectives to the background. The cities gradually shed local myths and highlighted a common Greek perspective (NAGY [1979] 1999, 116; 2012).

This evolution unfurled through the progression from smaller songs as specific, preludial hýmnoi (see Demodokos' song of Ares and Aphrodite) to hýmnoi taken from the totality of mythic contexts (see Demodokos' first and third songs in Odyssey 8; NAGY 2008/09, 313-342 [2§ 274-331]; 2009/10, 88-102 [I§ 210-241]); it then expanded to the regularized, monumental song in steady progression concerning a shorter period of time taken from a longer myth, such as the ménisstory of the Iliad, which represents fifty-one days in the ten years of the Trojan war. Growing Panhellenization and the associated trend towards monumentalization reflect a change in the ritual occasion. During the early Mycenaean and post-Mycenaean period, the occasion centered around an aristocratic meal; later the venue grew to the large annual festival of the Panionia in Mykale as a political event; finally, with the shift of political importance to the mainland, the cultural center became Athens. Thus, as part of Peisistratid cultural policy, the Homeric text came under Athenian control. Shortly afterward, due to the new regulations, the Panhellenic and monumentalized texts par excellence, the Iliad and the Odyssey, were regarded as Homeric, whereas other Cyclic epics, previously attributed to Homer as well, were ascribed to other poets. In addition, in accord with the new regulations, both Homeric epics of gigantic size and Panhellenic spirit were performed in their totality with alternating rhapsodes (NAGY 2008/09; 2009/10; FrAme 2009, 515-647; BIERL 2012).

A second force leading to a unified, monumental version of the story derived from the innate competition within the ritual occasion. Each aoidós wanted the top spot at the aristocratic courts. As the festival became political, with each reperformance a singer attempted to produce a perfect version with the fewest breaks and inconsistencies, trying to outdo the previous singer. Each performer strove to surpass the predecessor's fame in a chain of ongoing sequences. Simultaneously, the text became a unified entity in a unitarian or 'neo-unitarian' perspective. Cross-references, frequent anticipations and back references, hinges and joints in the compositional structure allowed a gradual coalescence into an organic entity (NAGY 2012, esp. 30). The agonistic spirit thus drove continual improvement of the text. Each reperformance endeavored to exceed the previous one, until people thought it was time to standardize the aesthetically satisfying product. Yet the text crystallized not at once but over a longer 'bottleneck' (NAGY 2001; 2012, 43), over the Panionic (8th/7th century) and Panathenaic periods (6th century BC). Moreover centrifugal and centripetal forces coincided: 'The wider this Homeric tradition spreads, the closer it gets to achieving its ultimate uniformity' (NAGY 2012, 43). The canonization did not end, and perhaps up until 
the age of Aristarchus a relatively small fluidity remained, attested through the so-called plus- and minus-verses in the papyri (NAGY 1996, 138-152).

With the crystallization around $600 \mathrm{BC}$ also came a shift from a text as transcript to a uniform script - best preserved in Athens - upon which all future reperformances were expected to rely. JANKo 1982, esp. 17, 192, 200-221; 1998, 1, 11-12, on the relatively firm grounds of linguistic statistics, shows that the Iliad has more archaisms and less Ionian intrusions than Hesiodic poetry; he thus argues for dating the Iliad to the 8th century BC, claiming that it stems from the dictation of an oral poem; but CAIRNS 2001a, 4, argues that a literate poet composed it. KIRK 1962, on the other hand, believes that the Iliad was composed in its totality orally in the 8th century, and that it then somehow came down with no major changes to the 6th century BC, when it was rendered in a literate form in Athens. Linguistic material and other instances, however, prove that 8th-century material has incorporated some characteristics of the 6th century (CAssio 1999, 76-78).

With the crystallization of the text at last, political leaders as well as audiences found themselves more and more in need of an author, and they created him retroactively. For this reason, Homer is finally well attested only in the last quarter of the 6th century, beginning with Xenophanes and Heraclitus. Thus Homer is in the end a construct, a charter myth in the sense of a re-projected first inventor (prôtos heuretếs), invented because people wanted to ascribe an ingenious individual author to the poem, which had gradually grown to perfection. In doing so they were influenced by their own experience with contemporary poems, whose authorship was definitely known. Thus the notion of Homeric authorship constitutes a matter of emergence. In the age of the 'death of the author' (BARTHES [1968] 1977), it is easier to cope with the assertion that the decisive factor is not so much Homer as an individual poet but the tradition that deals with real conditions and recomposition-in-performance by real singers and real audiences. This expands and evolves under different conditions into a continuous, consistent, organically perfect poem that we, especially in periods such as the Third Humanism, focusing centrally on the author, tend to ascribe to genius.

\subsection{A Summary of the Evolutionary Model, Modifications and Response to Criticism}

To summarize this complex model I provide the following sketch based on NAGY (1990, 80; 1996, 110; 1996a, 42): 


\section{Evolutionary or Gradual Textualization of Homer}

\section{Theoretical Phases of Appropriation}

1. 'Partial recomposition, performer L' (in a hypothetical series from A to Z) 'publicly appropriates a given recomposition-in-performance as his own composition.'

2. 'Performer $M$ stops appropriating the recomposition-in-performance as his or her own composition; instead attributes it to the predecessor $\mathrm{L}$; this attribution is then continued by successors NOPQ.'

3. 'In the process of successive recompositions by NOPQ, the self-identification of L' is

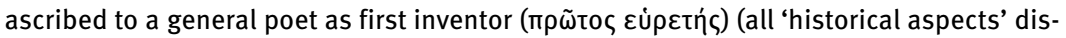
appear behind 'the generic aspects'). This equals a 'text fixation', since this version is regarded as the true (tò $\dot{\alpha} \lambda \eta \theta \dot{\varepsilon} \varsigma$ ) that must not be forgotten (see NAGY 1990, 59-61).

\section{Periods of Homeric Fixation or 'Five Ages of Homer':}

1. 'a relatively most fluid period, with no written texts' (second millennium to middle of 8th century BC);

2. 'a more formative or "pan-Hellenic" period, still with no written texts' (middle of 8th to middle of 6 th century BC, especially in Asia Minor);

3. 'a definitive period' of crystallization, 'centralized in Athens, with potential texts in the sense of transcripts' (middle of 6th to end of 4th century BC, beginning with the reform of the Homeric performance traditions under the Peisistratidai, that is the Peisitratid recension and regulations by Hipparchus);

4. 'a standardizing period, with texts in the sense of transcripts or even scripts' (for theatrical performances) (end of 4 th to middle of 2 nd century $B C$, beginning with 'the reform of the Homeric performance traditions' by Demetrius of Phaleron [317-307 BC];)

5. 'a relatively most rigid period, with texts as scripture' (as a canonical and holy text) (beginning with Aristarchus' edition of Homer shortly after $150 \mathrm{BC}$ and the end of the so-called 'eccentric' papyri).

Transcript $\rightarrow$ Script $\rightarrow$ Scripture

In line with the remarks above, I would argue that first potential transcripts appeared already in Period 2, and that the first scripts as sketches or notes for the still orally-based recompositions-in-performance by the rhapsodes appeared already in Period 3. Moreover, the setting in stone, the crystallization of the text, which came down through the 'bottlenecks' of the Panionia and Panathenaia, is probably almost complete by the end of the 6th century BC. At this point, the question of the emergent Homeric authorship becomes so vital that for pedagogical reasons one could no longer think in other terms. People spoke of Homer as the divine author, extrapolating from their own experience with contemporary poets. 
Some critics identify this extremely malleable model as a cultural, 'impersonal machine' (see NAGY 2012, 36) driven by 'impersonal forces of historical development' (CAIRns 2001a, 35). But each reperformance, as parole in the sense of an individual activation of the traditional system of langue, is 'interpersonal' (JAKOBSON 1990, 93, cited by NAGY 2012, 37), since the reperformances occur on 'real' occasions and between 'real' persons, i.e. individual singers - links in the chain of predecessors - and listeners. To deny the diachronic background by treating Homer as a typical written text to which 'familiar interpretative strategies' (CAIRNs 2001a, 53) can be applied thus severely limits our scope. We can certainly apply all the tools of literary criticism, but with such a refined oral theory in mind we have a hermeneutical surplus.

\subsection{Consequences}

\subsubsection{Neounitarian Quality and Malleability}

On these premises, it is possible to understand why Homer has always been praised as the best and most divine poet even though he appears as the first author in Greek literary history. Over the course of centuries, the reperformances could obviously be stretched out to monumental size and, despite the composite nature of the poem, improved, polished and ironed-out until finally taking shape in a continuous, elaborate narrative. With the introduction of the Greek alphabet, this artful composition could also be converted into the new medium as a transcript. This 'labor limae' (NANNINI 2010, 5) of an ongoing interpersonal perfection triggered by Panhellenization and agonistic occasion can be fittingly described as neounitarian, since the resulting artistry has an effect similar to the genius pursued by Unitarians, who allegedly composed at a desk and - in the process of production revised and polished his work over many years (thus WEST e.g. HT; 2011; 2011a; HöLSCHER [1988] 1990). Interestingly, HöLSCHER ([1988] 1990, 163-169, 184; see also 38-41), as a Unitarian, delineates a similar evolution from a 'simple story' to the monumental epic produced by the same principle of Panhellenization.

The evolutionary theory explains many features and mediates long-standing debates, accounting for why epic occasionally imitates song and choréia, e.g. in laments. That is to say, song is older than the regulated recitative (parakatologê) of the hexameter, derived from a normalized lyric glyconic rhythm, the pherecratean with a spondaic beginning and an internal expansion of three dactyls (NAGY 1974, 49-102; 1990, 459-460). Furthermore, the Homeric Kunstsprache consists of diverse strata, with a few very old Mycenaean forms, a larger Aeolic repertoire and, most significant, the Ionic dialect dominant around the time of crystallization in the 6th century BC. 
NAGY's model makes LATACZ' ([2001] 2004, 250-277) claim that the hexameter could preserve certain facts from Mycenaean times conceivable, but it also makes it clear that, due to ongoing transformations, Homeric epic can hardly be a true 'newspaper-report' of the past (see LATACz [2001] 2004, 264-265; RAAFLAUB 2003, 310-311; on the question of continuity and the Trojan war, see RAAFLAUB 2005, 58-60; 2006, 451-455; ULF 2010, 302-303). Instead, it seems probable that only small bits of information ('Restsplitter'/'fragments': LATACZ [2001] 2004, 250-251) survived the filter of reperformance from the distant past before the cultural breakdown and the ensuing Greek immigration and cultural revival in Asia Minor. Only a nucleus can thus have been transmitted through the ongoing adaptations; the rest was probably conflated with imaginary scenarios, while most of the socio-cultural texture was adapted to the archaic contemporary setting of the formative Panionic and even more the crystallizing Panhellenic period (RAAFLAUB 2003; 2005; 2006; ULF 2010, esp. 306-310). It is thus likely the case that later strata, such as allusions to Athens and its dominant role, could be incorporated. The same can be applied to more recent developments, like the introduction of the fighting-strategy of phalanx formation or the polis system with its democratic structure. Moreover, allegedly later additions of the 6th century like the Doloneia or Odyssey 24 can be viewed and interpreted as authentic. ${ }^{3}$

The Doloneia in particular has been almost unanimously excluded from the text of the Iliad. Because this evolutionary model renders Homer a multiform text, however, a recent boom of research claims that Iliad 10 fits perfectly into the surrounding events and is part of the tradition (DuÉ/EBBotT 2010; BIERL 2012a; LAVIGNE 2008; see also MARTIN 2000, 61-62). The unusual features of the Book stem instead from its narrative function and subgenre. Iliad 10 constitutes a diachronic regression into atavistic times, linking to the perspective of ambush, death, night and the 'Other'. Its narrative function aims at symbolically underscoring the critical transition from the first short day of battle of the mênis-plot to the long and decisive second one, from darkness to light, from depression to new confidence, and from death to life (DuÉ/Еввотt 2010; BIERL 2012a).

\subsubsection{Traditional Art as an Oral Poetics of Ellipsis}

LORD 1960, 94, already emphasized the 'pull in two directions' with each performance, the actual song and the evocation of previous instantiations of the system, horizontal combination and vertical selection, in the terms of the Prague

3 On the justice scene on the shield, see NAGY 2003, 72-87; the end of Od. 24 has certain similarities to the Athenian polis discourse of the Oresteia. 
school (NAGY 1996, 2 n. 7). NAGY 1996, 50, underlines the dynamic interaction of diachrony in synchrony as follows: 'From this point of view each occurrence of a theme (on the level of content) or of a formula (on the level of form) in a given composition-in-performance refers not only to its immediate context but also to all other analogous contexts remembered by the performer or by any member of the audience.'

This is exactly what Foley (1990; 1995; 1999) pins down as 'traditional referentiality' (e.g. 1997, 167), as a pars pro toto or metonymic relation: behind and between the signs is a diachronic dimension that opens up the totality of possibilities - alternative narrative routes, different exits and instantiations. FOLEY develops a new oral poetics as 'traditional art' (1999) that does not respond to metrical needs but should be understood on its own terms of craftsmanship. The epic 'word', the reč, of the guslar is the unit of an utterance; it is not the small element in grammatical terms but an entire verse, a scene or a whole song. The performers claim that they never change tradition, although the reč is constantly transformed in the ongoing chain of reperformances. Words are 'nodes in a network of signification [...] signs that point the way down the Homeric óime, the song-path' (FoLEY 1997, 167). FolEy refers to formulae, type-scenes or story patterns as 'registers', traditional chunks that the performer acquires to delineate the ever-recurring frame with an 'unmatched economy' (1997, 172) - NAGY 1997 calls this 'elliptic' because the 'special brand of meaning' (FolEy 1997, 173) goes diachronically down the scale to evoke all sorts of situations and resonates with all meanings in the echo-chamber of signification, signs and sếmata.

\subsection{Relevance to Today: Multiforms, Web and Hypertext}

During the time of the conception of the first German edition of the Prolegomena, the internet began to conquer global communication. In addition, postmodern criticism and ideas such as intertextuality and deconstruction anticipated a media revolution: BAKHTIN (1929) 1984 speaks of polyphony, and French structuralists like Barthes and Kristeva introduced terms like network, web, paths and open-endedness in the signification process. Furthermore, BARTHES (1968) 1977 thematized the 'death of the author' (see also Foucault [1969] 1979). All these features are realized in the internet, where no center or linear perspective exists, but nodes of interconnectivity define a plurality of choices in a virtual galaxy of visual windows. In this labyrinth, organic order is lacking, meaning the user can interact with the medium and shift between numerous levels. Furthermore, no single author controls the dissemination of meaning or the user as reader (see BAKKER 2001), but users dynamically interact with free-floating information. 
As is well known, the reader composes his or her information through the very process of use, clicking through sites in permanent mouvance (see ZUMTHOR 1972), evoking the diachronic context and material in new synchronic cuts.

It goes without saying that some of these insights are traceable in LORD 1960 and his followers, who initiated the new trends in orality. On the one hand, we hear of multiforms, mouvance, transference and the interaction of myths and texts in the galaxy of tradition. The hypertext and internet accordingly often serve as metaphors to convey the dynamics of orality (BAKKER 2001; FOLEY 2012). On the other hand, the Center for Hellenic Studies treats Homer as multitext, setting up a digital edition with clicks to as many variants as possible, all equally valid in a performance tradition (see http://chs.harvard.edu/CHS/article/display/1169 and http://www.homermultitext.org/; retrieved 9. 1. 2015). A multitext edition, then, takes into account the model of an evolutionary Homer whose text refuses to be set down and analyzed with the usual methods of textual criticism and a stemma-theory by Lachmann. All in all, the web and the weaving process provide, in both realms, dominant metaphors and visual emblems of text (from texere 'to weave') which describe the specific process of patterning - incorporations of and allusions to other texts drawn from the labyrinthine galaxy of tradition.

Recent research on oral theory by critics like BAKKER, MARTIN, NAGY and FolEy opens the horizon to a new and liberating oral poetics and aesthetics of an 'immanent art' (Foley 1991) that can be analyzed in every passage of the Iliad. Homer, understood as a 'culture hero who is retroactively credited with the sum total of the entire cultural institution' (BAKKER 2001, 156, paraphrasing NAGY 1996, 76) must be viewed in the perspective of an emergent authorship which, due to Panhellenism and agonistic elements, gradually narrows down the total open-endedness, with its endless exits and alternative routes, to a perfect, organic plot. This trajectory finally merges with the unitarian approach to the poet as genius. All things considered, the starting point of Western literature is based in a tradition that can be legitimately analyzed in terms of author and literature. Yet behind the author lies much more, a deep diachronic structure that reveals many new paths. 


\section{Further Topics and Related Themes}

On these premises, several other topics have been highlighted over recent years:

\subsection{Biography}

It becomes more and more evident that the Imperial biographies that treat Homer, particularly the Certamen and the pseudo-Herodotean Vita, are not mere fantasy spun from the epics, especially the Odyssey, but resonate somehow with the branch of then contemporary Homeric scholarship, reflecting insights in the diachronic prehistory. Both Lives highlight the improvisational aspect within composition-in-performance, and hardly refer to the compositional act in terms of gráphein (writing) (NAGY 2009/10, 29-55 [I§ 55-136]). Moreover, in Homer’s long circuit in the Vita Herodotea we can detect reflections of the emerging authorship. Thus the story in some ways mirrors the potential loss of control of the performance now transcribed in exchange for a living by someone planning to recite it as a rhapsode elsewhere. Homer as ingenious performer, then, pursues the thief to Chios where the Homeridai have their school. In addition, the Vita Herodotea exhibits an acute awareness of an Aeolic past in Smyrna. This city, pinned down as a potential point of origin, was originally part of an Aeolic Dodecapolis (Hdt. 1.149.1) but was later conquered by the Ionian city Colophon. Smyrna thus functions simultaneously as the hinge to the Ionic league of cities with their common festival of the Panionia celebrated in Mykale. As the cultural importance of Asia Minor diminishes, the tradition, following the same trajectory as Homer in the story, moves to Chios, then to Samos under Polycrates and finally to Athens, the new cultural Panhellenic center, where the Peisistratidai bring the tradition under control (NAGY 2009/10, 133-146 [II§6-41]).

\subsection{Politics and Value Orientation}

Doubts have arisen as to whether the Homeric epic merely represents a 'self-

affirmation' of the aristocracy and a pedagogic appeal to their noble ideal cast in monumental song, valid in particular during the Mycenaean period before the cultural decline around 1150 BC. According to this fixed sociological function, epic would have somehow 'frozen' its old value orientation, as heroism was at that point only a matter of the past (LATACZ 2013, 69-70, pace ULF 2010, esp. 302-310, and RAAFlaub 2003, 310-311; 2005, 59-60; 2006, 453-455). With evolutionary theory, however, we can mediate between divergent positions, since the gradual 
Homeric textualization adapts to new socio-political circumstances in ongoing reperformances. Despite the radical socio-economic changes and the questioning of aristocratic leadership, Homeric epic is not superseded and does not come to a logical end after 750 BC. Is it thus likely that Homer was later fundamentally 'misunderstood' (LATACZ 2013, 57) in regards to his 'reactionary' social function, allowing the epic genre to live on as an 'empty form' ('Leerform') conveying many other contents (LATACZ 2013, 77)? To the contrary, as argued above (see 34), the Homeric text appears to incorporate to a certain extent the new values of a polis ideology present during the period of crystallization in the 6th century BC, and remained a dynamic and vital field that appealed to contemporary audiences.

\subsection{Etymologies}

Etymologies, or the science of the étymon, i.e. the true sense, can help unearth the deeper sense buried in linguistic diachrony, even reaching far back to Indo-European roots, with regard to specific figures in the evolving plot. For example, the name of Achilleus, the main hero of the Iliad, might be derived from áchos and láos, ${ }^{4}$ the one who brings pain and grief to the people in a double sense: a) to his troop of Myrmidons and the Achaians with his retreat; $b$ ) to the Trojan enemies with his enormous strength as a wild fighter driven by a desire to avenge the death of his friend and surrogate Patroklos (NAGY [1979] 1999, 69-83).

\subsection{Myth}

In 'small-scale' and traditional 'societies', such as we find in the later Bronze Age and early formative phase in Asia Minor, myth and ritual in interaction and correlation constitute marked discourse (NAGY 1990, 31). The cultic setting or ritual occasion of the performance, moreover, frames the heroes' mythic narration in an idealized past. As argued above, the entire Iliad can be understood as myth (MARTIN 1989), while figures inside the story tend to emphasize their

\footnotetext{
4 For a different explanation, see LATACZ (2001) 2004, 303 n. 26: 'It is suggested that even the name of "Achilleus" himself, for which no rational etymology has yet been found, may be traced through a possible connection with the name "Achaia". As early as 1958, von Kamptz (1982)

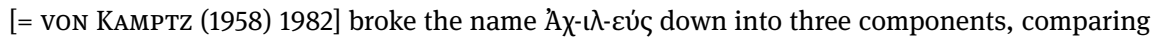
$-\imath \lambda$ - with the "pre-Greek Anatolian suffix -il" in the Trojan name $\tau \rho \omega \iota \lambda$ os, and affixing these to the "pre-Greek stem" 'Ax-.' The name is already attested in Mycenaean: VeNTRIS/CHADWICK (1956) 1973, 529: $a-k i-r e-u$ = Achilleus; see also in MYC: as dative $a$-ki-re-we.
} 
speech-acts through mythic examples. We thus have a myth-in-myth constellation, or in NAGY's 1996a, 137, words: 'the outer narrative that frames mythological exempla is itself a mythological exemplum, on a large scale.'

In addition, numerous myths come from the infinite web of tradition, and the performer metonymically alludes to and partakes in this mythic galaxy through elliptical forms; or to put it as SLATKIN (1991) 2011, 20, does, the poet incorporates into his narrative another discourse, one that makes its appearance on the surface of the poem through oblique references, ellipses, or digressions, evoking for his audience themes that orient or supplement the event to the poem in particular ways.'

Myth shares with traditional narrative the feature of being authorless. Both are also transformed through endless variation and combination with a stable nucleus of motifs. In addition, mythic themes and patterns litter the Homeric epic, and LORD has already emphasized their structuring presence. In both the Iliad and the Odyssey we thus encounter variations of death and rebirth, disappearance and reappearance, search and retrieval, separation and reunion, hiding and epiphanic arrival (LoRD 1960, 158-197).

\subsection{Ritual}

On the ritual side, many critics today highlight the ephebic pattern and initiation motifs, theoxeny, scenarios of the Other, relapses into the primordial or atavistic, new year and king ritual, agonistic reversals, elements of supplication, lament, góos or thrếnos, marriage, choréia and dancing, feasting, sacrifice, prayer, epiphanies, remnants of solar imagery, burial and hero cult.

In the vein of mythic-ritual poetics (BIERL 2007), some Homeric scenes might be successfully read as symbolic expressions of the Other, rites of passage, epic encounters with death and reflections of a katábasis (for Il. 24, see HERRERO DE JÁUREGUI 2011; for Il. 10, see BIERL 2012a) or shamanic excursion. The rituals are both exhibited and incorporated to highlight extraordinary danger and to symbolically underline the contrast to normal life.

The entire story pattern or genre of nóstos not only constitutes a return home

from a military expedition but a special 'return from death to life' and return to 'light' (FrAme 2009, 23-58, esp. 39-45; see also 1978, 134-152, and NAGY 1990a, 218-219; 2013, 275-278 [9§ 1-7]). Thus Odysseus' adventures must be interpreted as endless variations on the encounter with death, woven in an artful, patterned order that does not necessarily indicate a writing poet but a monumentalizing tradition, which lengthens the essential and traditional motif of death on the basis of retardations, variations and combinations (BIERL 2008; HöLSCHER [1988] 
1990, 103-185). One could also argue that the Trojan War itself represents a confrontation with death, whence the heroes must return to life and light. On the one hand, Achilleus confronts the fundamental choice between kléos or nóstos - he can either die heroically and have imperishable, unwithering glory (kléos áphthiton) transmitted by epic song tradition, or return home without glory and die of old age. On the other hand, his withdrawal due to his ménis becomes a symbolic death, which causes multiple deaths on the battlefield; Patroklos, his therápōn, surrogate or alter ego (see NAGY [1979] 1999, 33, 292-293; 2013, 146-154 [6§1-23]), dons Achilleus' armor to compensate for this voluntary absence and dies early. Achilleus then reappears on the battlefield - a scene we can also interpret as a nóstos - and transforms his mếnis from an expression of passivity to active, furious revenge. And in ritualistic terms, nóstos can be seen as a reintegration into society with an anticipated, implicit immortalization as cultic hero.

\subsection{Hero Cult and Epic Heroes}

Panhellenization acts on all these mythic and ritual elements so that they tend to almost disappear behind a new, realistic veil. Yet they remain operable in an implicit fashion. A particularly good example is hero cult. The local and epichoric cult of a heroic figure after his death tends to be dropped in Homeric epic, but implicit allusions or anticipation of future immortalization can still be elaborated (NAGY 2012, esp. 47-71).

Heroes are mortals immortalized only after their death, receiving a local grave and cult. The sêma, the grave, also means the sign that bears the entire significance of hero cult, becoming the medium through which to communicate with the hero by libations of oil, milk, honey and blood, as well as chthonic sacrifice. Moreover, the hero receives the right portion of the quartered victim, his géras, thrown into a pit (bóthros). The participants expect fertility as a reciprocal response to this action. This normal pattern, however, is 'defamiliarized' and transformed by the Panhellenic pattern. The local hero becomes an epic hero whose traits appear completely human on the surface, his main feature being his mortality; as a consequence, he attains immortality mainly through heroic death, which entails 'eternal, unwithering' fame (kléos áphthiton). Thus the hero, immortalized through death, becomes almost identical with the kléos áphthiton he receives via epic song in the eternal chain of future reperformances. Through his death on the battlefield, therefore, the hero encounters his last and decisive ordeal and, as expected, does not live a long life but dies prematurely, pan$a$ (h)ốrios (see Il. 24.540), sometimes still at the ephebic age. Moreover, like all heroes (BRELICH 1958), he is extremely ambivalent, both good and terrible at the 
same time. In the case of Achilleus, the negative and problematic side manifests itself in his manic frenzy of revenge (Iliad Books 19 to the beginning of 24); this is exaggerated to the utmost when he longs to eat the flesh of his enemy (Il. 22.346347), a powerful allusion to Dionysiac manía in myth (see NAGY 2013, passim, esp. 46 [1§54] and 2005, 86-89; 2006, § 76-116).

In the Panhellenic perspective, moreover, epic heroes stand in antagonis-

tic opposition to the god, with whom they are connected on a cultic level (NAGY 2013, 333-334 [11§45]). In our example, Achilleus represents the ephebic counter-part of Apollo, the god of ephebes, and fights against Apollo, with whom he shares common cults. In Iliad 9.189 Apollo and Achilleus associate with one another when the hero sings to the Apollonian lyre about the 'glories of men' (kléa andrốn). Thus the god reflects the hero, and the hero the poet, who merges with him through the performance of kléos, the medium and essence of epic song (NAGY 2013, 55-69 [2§ 29-71]).

Moreover, the fierce, brutal battle scenes in epic stylize sacrificial division.

Rather than watching every detail of the sacrificial victim's portioning, the audience of the Iliad is visually confronted with detailed descriptions of heroes' bodies brutally mistreated, lacerated, transfixed, perforated and slashed. Through these brutal deaths, the epic compensates for the necessary and usual sacrifice in normal hero cult (NAGY 2013, 11-12 [0§13-15], and 2006, §111-114).

\subsection{Possible Influences from the Near East: Oriental Myths and Narratives}

The diachronic perspective can also shed light on the allusive dialogue between Homeric epic and Near Eastern parallels, in particular Gilgamesh. The Sumerian tradition dates back to the third millennium BC. Sumerian was then replaced by Akkadian (with Babylonian and Assyrian as dialectal variants), and Gilgamesh appeared, in its archaic version, in Old Babylonian in the early second millennium (2000-1600 BC), its influence spreading throughout the Levant in the 14th and 13th centuries BC, especially in Hittite translation. The standard version of the twelve-table epic, its revised form, was ascribed to the mythic poet Sinleqe-unnini around $1200 \mathrm{BC}$, but the real end-redaction probably took place later in Uruk, and not before the 7th century BC do we have the most complete copies of this canonized epic as part of the library of King Assurbanipal (669-627 BC) in Nineveh (NOEgEL 2005). The epic thus circulated in a very fluid phase during the Bronze Age, when connections with Greece are attested. But its greater influence might be attributed to the period following the crisis around $1200 \mathrm{BC}$, when a flourishing new oriental world took shape in the first centuries of the first millennium, 'a koiné of culture from Mesopotamia via Syria/Palestine to Anatolia 
and Egypt,' with 'channels' (BURKERT 2005, 301) of exchange and possible transmission via Phoenicia (with the introduction of the alphabet), Lydia and Egypt (BURKERT 2005, 291-295; see also SASSON 2005).

55 There are striking parallels in style (i.e. long verses, formulae, type-scenes, assemblies of gods, battle scenes) and narrative structure. Such parallels were explored by JENSEN 1906/28 (Pan-Babylonian exaggeration) and later in our generation more seriously by scholars such as BURKERT (1984) 1992; 2005; MORRIS 1997; WeSt 1997; PATZEK 2003.

56 Motif-transference or the direct influence of the Iliad on smaller story lines and structural elements has been repeatedly demonstrated (BURKERT [1984] 1992; 2005; WEST 1997; CURRIE 2012). One of the most conspicuous similarities is found in Enkidu, Gilgamesh's dear friend, who dies as a surrogate for him, like Patroklos for Achilleus (see LORD 1960, 197, 201; CURRIE 2012, 550-551). The question remains how to explain such parallels. Do overlaps exist in the very early period? Should we depart from neoanalytic approaches of early or later incorporation in oral, semi-oral or literary form in the formative or even crystallizing phase? A bilingual oral transfer or code-switching is quite unlikely, as these oral specialists are completely immersed in a formulaic system closely linked to their own language and culture. Or should we lend credence to the quite literacy-based hypothesis that bilingual Greek poets and scribes served as intentional, multicultural mediators in Northern Syria or Cilicia in the middle of the 7th century BC? SchrotT 2008 thus wildly speculates that Homer was an Akkadian-speaking Greek scribe and eunuch, who lived not in Asia Minor but in the Cicilian city of Karatepe and was in the service of Assyrian dynasts; ScHRotT also claims that Homer took his inspiration from the Cilician revolts against the Assyrians (715, 705-696, 676 BC) and from the geographical ambience, when he compiled the fictionalized events of the Iliad on the basis of Near Eastern epics around 660 BC. ${ }^{5}$

Despite apparent similarities, we must not forget the differences. Cross-cultural comparison also makes it clear that such parallels are often typological and can be detected in numerous epic and narrative traditions around the world. Yet it should be stressed that the relation of the Near Eastern material to Homer is not genealogical, that is, based on cognate, diachronically and synchronically proven structures of derivation, since no clear descent of a closer linguistic relationship with the Greek Iliad can be traced, outside of indirect Hittite or Luwian influences. Rather, contact between Near Eastern and Greek tradition occurs late in the 7th century, a historical given that comes after the main transformations in the Iliad are already complete. But some fluidity remained, as well as room for

5 For a fair refutation of these speculations, see VISSER 2008, 80-83. 
reciprocal appropriation between the analogous traditions, although some parallels are not necessarily historical and must be classified as typological (NAGY 2005, 71-76; 2006, § 1-30).

Nor can what we admire in Homer stem from the Near Eastern texts. Despite

a long canonization and development toward greater human values and more homogenous structure, Gilgamesh lacks the human dimension of Achilleus, and the Akkadian epic never attains the organic form for which Aristotle and all critics after him praised Homer (SLEZÁK 2012, 217-239, esp. 234-239).

It is obvious that a very early scribal fixation in cuneiform, which facilitated only revisions - again always written down on tablets - occurred during the phase when the Homeric epic was still in its fluid prehistory. Writing froze the cultural narration, and a fossilized text did not possess the potential an oral tradition has. As seen above, the emerging authorship affects the elaboration of the evolving product of artistry. The progress of quality thus stems from a long chain of recomposition of the same 'word', which is constantly transformed due to agonistic and Panhellenic influences. We can accordingly venture that extended oral fluidity entails a qualitative jump under specific socio-political and polycentric conditions. Consequently, due to a lack of hierarchical and monarchical structures, the Greek people became aware of belonging to a common culture and ethnicity. This process lead to new occasions, i.e. public festivals with agonistic elements, inducing a transformation toward monumentalized, cohesive forms of narration. On the other side, literary fixation more or less froze the early standard of the narration, and centralized dynastic structures favored text as an emblem of the divine power of an all-mighty king.

\subsection{Mise en abyme and Metanarrative Reflection}

Metapoetic awareness or emblematic self-referentiality are the apparent features of a highly aestheticized literary art such as we encounter in the poetry of the late 19th and 20th century and in recent, postmodern times. Critics of former generations would thus never have reckoned with the existence of such sophisticated techniques in oral poetry when they judged its aesthetics in primitive terms (NoTopoulos 1949). In the last two decades, however, it has become increasingly evident that the Iliad and, even more so, the Odyssey tend to self-referentially reflect on their own poetic tradition (e.g. SEGAL 1994, 85-183; RENGAKos 2002, 189-191; DE JONG 2006).

In this vein, critics have recently approached parts of these epic works as

such, e.g. the long ékphrasis of the Shield in Iliad 18 (DE JoNG 2011) and the scene of Achilleus playing cithara in his tent and singing about the 'glories of men' (Il. 
9.189) (NAGY 2013, 55-59 [2\$29-40]). Other examples are found in the idealized aoidói Demodokos and Phemios as self-reflective figures of the performance tradition. Even Odysseus himself is several times associated with a singer; Demodokos' song of Ares and Aphrodite (Od. 8.266-366) in particular alludes to earlier stages of the Homeric epic, helping to shape the plot in a metanarrative fashion. Demodokos, moreover, stands in competition with Odysseus, who narrates his Apologoi in the new mode that reflects the situation following the reform of Homeric performance traditions. In the same way that Penelope's famous cunning (mēchánēma) of weaving symbolizes the process of textualization (CLAYTON 2004; BIERL 2004, 111), so does the artful web of invisible chains produced and installed by the master blacksmith contain metapoetic implications, and functions as an internal mirror of the entire plot (BIERL 2012). Through 'intratextual' strategies the Iliad and even more so the Odyssey - tends to frame the inner contents of speeches with outer events, juxtaposing matters by creating special meaning through performative adjacency and similarity- and opposition-effects, sometimes even producing forms of a mise en abyme, 'a text-within-text that functions as microcosm or mirror of the text itself' (MARTIN 2000, 63-64, quote 63).

Self-reflective and metanarrative elements, after all, are not as surprising as they might at first appear, since our Homeric epic is a late, crystallized product, the culmination of a long history of reperformances in ongoing transformations. As seen above, the kléos of the heroes acts as the medium and essence of the performance tradition. Thus, whenever kléos is mentioned, the performance references itself, since with each reperformance the glory must be recalled and reactualized via the Muses who inspire each singer with the memory of the story to be reperformed (see also DE JoNG 2006); the concept of kléos is the 'medium of total recall' (NAGY 2013, 50 [2\$12]), and as long as the idea of performance culture thrives, the tradition will never die and thus projects its own trajectory into the future.

\subsection{Memory}

Against this backdrop, the study of memory and commemorative processes emerges as another major issue in recent Homeric scholarship. This highly interdisciplinary field extends from anthropology, cognitive psychology and neuroscience to archeology, history and Homeric linguistics. It explores the basic oral discourse, showing how speech formats that help human beings structure and perform routine acts of daily life are stylized into Homeric type scenes (MINCHIN 2007). The above mentioned (see 15) cooperation between cognitive science and oral poetics can yield stimulating new directions in Homeric text and culture. 
BAKKER 2005 stresses the visualizing, presencing and cognitive dimension of reperformance in recall. Detailed descriptions of material objects or of a landscape can provide a historical consciousness and shed light on the commemorative act in a self-reflective manner (GRETHLEIN 2008; MINCHIN 2012a). Furthermore, in autobiographic recollections of the past heroes like Odysseus can shape their own sense of the past and instrumentalize the elements using the pragmatics of actual discourse (e.g. BIERL [in press]). Minchin 2012 also explores how personal, social, collective and cultural memory define the Iliadic personnel and their speeches. In a new project, she promises fascinating results by applying cutting-edge research on memory, recently assembled in volumes such as BOYER/ WERTSCH 2009, on Homeric studies.

\section{Conclusion and Prospect}

With the new trends described above, Homeric scholarship makes its way $\mathbf{6 4}$ into the future. And by incorporating all these exciting approaches, both the German and the English edition of the present commentary, in their hermeneutic 'reperformance' and re-digest of earlier and recent research results, keep the tradition of this outstanding text alive and fresh for every rereading by their users. 